\title{
Algumas Palavras sobre o Nasf: Relatando uma Experiência Acadêmica
}

\author{
A Few Words about the NASF: Reporting an \\ Academic Experience
}

Inajara Carla Oliveira ${ }^{I}$ Renata Mancopes Rochall Luiz Roberto Agea Cutolo

\author{
PALAVRAS-CHAVE \\ - Ensino. \\ - Extensão. \\ - Atenção Primária à Saúde. \\ - Educação Médica.
}

Recebido em: 27/03/2012

Reencaminhado em: 24/08/2012 Aprovado em: 02/10/2012

REVISTA BRASILEIRA DE EDUCAÇÃO MÉDICA $574 \frac{\sin (4): 574580 ; 2012}{36}$

\footnotetext{
${ }^{I}$ Universidade do Vale do Itajaí, Santa Catarina, SC, Brasil.

"I Universidade Federal de Santa Maria, Santa Maria, RS, Brasil.
}

\begin{abstract}
Created by Ordinance Law 154/GM of 24 January 2008, the Family Health Support Center (NASF) aims to increase the capacity of Family Health Strategy (ESF) teams so as to meet the needs of the population within each team's coverage area. Based on the principles of comprehensive and interdisciplinary care, what distinguishes this from other programs in operation is the proposal for a broad-scope clinic. Professionals from diverse areas, such as speech therapists, physiotherapists, nutritionists, physical educators and psychologists form the NASF. These professionals are admitted as required by each region covered by the family health teams. This new field opens a door for these professionals to work within a matrix framework, playing a unique role which should be developed since undergraduate training. In view of this proposal, this paper reports the observations of a student speech therapist about her experience acting in a Family Health Support Center pilot project at Vale do Itajaí University, Santa Catarina, Brazil in 2008.
\end{abstract}

ABSTRACT 


\section{INTRODUÇÃO}

Criado pela Portaria 154/GM de 24 de janeiro de 2008, o Núcleo de Apoio à Saúde da Família (Nasf) visa aumentar a capacidade das equipes de Estratégia da Saúde da Família (ESF), respondendo às necessidades da população abrangida pelo território delimitado para cada equipe. O trabalho no Nasf é baseado nos princípios da integralidade e da interdisciplinaridade. Portanto, o que o diferencia dos outros programas já implantados é a possibilidade de trabalhar com a proposta de clínica ampliada.

Pode-se dizer que a proposta dos Nasf, em boa medida anunciada na Portaria do Ministério da Saúde no 154/2008, propõe ampliar a abrangência e o escopo das ações da Atenção Básica, bem como sua resolubilidade, apoiando a inserção da Estratégia de Saúde da Família na rede de serviços, tendo o processo de territorialização e regionalização a partir da Atenção Básica ${ }^{1}$.

O Nasf é composto por profissionais de diversas áreas, entre eles fonoaudiólogo, fisioterapeuta, nutricionista, educador físico e psicólogo. A seleção dos profissionais para compor as equipes dos Núcleos se dá conforme a necessidade de cada região abrangida pelas equipes da ESF.

Várias são as atividades a serem desenvolvidas pelos profissionais que compõem os Nasf. O diferencial do trabalho é o apoio às equipes da ESF. Toda proposta deve ser compartilhada com a equipe - seja ela de atendimentos individuais, atenção domiciliar a acamados, atendimentos em grupo, oficinas de educação em saúde ou estudos de caso, entre outras.

Como profissional inserido neste campo, o fonoaudiólogo deve atuar promovendo a saúde e a qualidade de vida. Essa perspectiva implica fazer da comunicação e da linguagem, na prática cotidiana, uma ação política concreta que vise à produção de um saber social e culturalmente comprometido com o partilhar de bens comuns. E comprometido, ainda, com a intervenção e a transformação da realidade de educação e saúde da população que concorram para a superar as iniquidades sociais e a exclusão, com melhoria da qualidade de vida e promoção da saúde ${ }^{2}$.

Além disso, esse profissional pode atuar com estratégias de prevenção de doenças junto às ações multiprofissionais voltadas à saúde da mulher, da criança, do adulto e do idoso, trabalhando de forma direta e indireta com essas populações. De forma direta, pode atuar realizando programas de orientação no desenvolvimento da linguagem, da audição e das funções estomatognáticas (sucção, mastigação, deglutição, fonoarticulação e respiração), por exemplo ${ }^{3}$.

Cabe também ao fonoaudiólogo inserido no Nasf realizar atenção domiciliar e atuar em creches e escolas, prestando assessoria e orientação, organizar grupos de promoção da saúde e de prevenção da doença, discutir casos e desenvolver projetos terapêuticos singulares com a equipe.

De maneira geral, pode-se dizer que as atividades realizadas no Nasf são basicamente um exercício de integralidade, uma vez que todas as ações devem partir da necessidade da população atendida, e isto deve servir como guia em todas as intervenções. As ações nessa perspectiva são eficazes, pois vão ao encontro dos anseios e desejos dos usuários do serviço, pautadas na realidade concreta da população e não baseadas nas concepções dos profissionais acerca do real.

Atualmente, os serviços de saúde têm mostrado pouca capacidade de resolutividade frente às necessidades de saúde dos indivíduos. Apresentam dificuldades de acesso da população, fragilidades na criação de vínculos e responsabilizações, bem como uma prática marcada pela frieza dos profissionais e pouca participação da população.

Quando se fala de cuidado, o vínculo consiste no ponto de partida, que necessariamente perpassa a capacidade de ouvir o usuário e tratá-lo como um sujeito com desejos, crenças e temores, para, então, a partir daí, acolher sua demanda ${ }^{4}$.

As características dos serviços de saúde e a complexidade que envolve as ações desenvolvidas no processo de cuidado pela equipe e por cada um devem ter como base um conceito de saúde amplo, que vá além da ausência de doença e inclua bem-estar físico, mental, social e espiritual. Deste modo, compreender saúde em sentido amplo inclui paz, habitação, educação, alimentação, renda, ecossistema estável, recursos sustentáveis, justiça social e equidade ${ }^{5}$

Diante desta realidade, são necessárias mudanças na organização do funcionamento do sistema de saúde pública oferecido à sociedade. Para tanto, além do Nasf, o Ministério da Saúde criou, em parceria com o Ministério da Educação, alguns programas voltados para a educação dos profissionais da área da saúde, como, por exemplo, a estratégia de Integração Docente Assistencial, o Programa de Reorientação Profissional (Pró-Saúde) e, mais recentemente, o Programa de Educação pelo Trabalho para a Saúde (PET-Saúde) ${ }^{6}$

Tais programas têm como fio condutor a integração ensino-serviço- comunidade. Eles servem como instrumento para a qualificação do serviço dos profissionais da saúde e são um incentivo aos trabalhos de iniciação científica, proporcionando vivências aos acadêmicos de graduação, indo, portanto, ao encontro das necessidades do Sistema Único de Saúde (SUS).

A Universidade do Vale do Itajaí (Univali) tem experiência em participação nestes movimentos e iniciativas do governo. A história do envolvimento desta universidade com a saúde comunitária remonta à implantação dos primeiros cursos da área da saúde. 
Vale destacar que, antes da proposta de criação dos Nasf, a Univali foi pioneira no Brasil ao implantar o Núcleo de Atenção Integral na Saúde da Família (Naisf), tendo realizado suas primeiras discussões em 2003, ainda incipientes, e implantado como projeto de extensão, em 2005, com incentivo da Portaria ministerial no 1065/GM de 4 de julho de 2005.

Em sua primeira versão, o objetivo do Naisf era garantir suporte técnico em áreas específicas - Atividade Física e Saúde, Saúde Mental e Reabilitação — às equipes da Estratégia de Saúde da Família responsáveis pelo desenvolvimento de ações básicas em saúde. Entretanto, essa proposta não teve continuidade, principalmente devido à diversidade de entendimento acerca do projeto.

Considerando a experiência vivenciada em 2005 e frente à importância e à inovação da proposta dos Nasf, a Univali no ano de 2008, três meses após a notificação da Portaria ministerial da criação dos Nasf —, em parceria com a Secretaria de Saúde do município de Itajaí, se propôs a realizar um projeto piloto do Núcleo de Atenção à Saúde da Família, de forma integrada ao Distrito Docente Assistencial (DDA).

O DDA funciona como ambulatório de atenção familiar e comunitária, conta com três equipes de Estratégia de Saúde da Família do município e propicia a atuação de alunos por meio de estágios curriculares. Os estágios integram oito cursos da área da saúde: Enfermagem, Medicina, Fisioterapia, Fonoaudiologia, Psicologia, Nutrição, Farmácia e Educação Física. Na proposta do DDA evidencia-se uma forte ligação com os princípios da reforma sanitária, e um de seus objetivos é inovar os cenários de atuação, com a finalidade de promover mudanças na formação acadêmica.

O DDA demonstra potencialidades na consolidação de um modelo de atenção pautado pela integralidade, cujos objetivos visam à superação do modelo biologicista preventivista, tanto na formação dos alunos quanto na atenção à saúde das pessoas assistidas por essa instituição.

O objetivo deste trabalho é relatar a experiência da atuação de uma acadêmica de Fonoaudiologia no referido projeto piloto do Nasf, durante o terceiro período do curso.

O relato será dividido em três temas: visão do sistema, visão pedagógica e visão pessoal, a fim de aprofundar as discussões sobre a atuação nesses diferentes aspectos.

\section{Visão do sistema}

Em 2008, graças à oportunidade de estagiar voluntariamente no projeto piloto do Nasf do DDA, na área de Fonoaudiologia, a acadêmica pôde acompanhar a realidade da atuação na Atenção Básica.

O objetivo do projeto era fornecer apoio matricial a três equipes da ESF. Para entender a proposta do apoio matricial, era necessário discutir uma nova visão de atuação em saúde, designada por diversos autores como Clínica Ampliada.

Esse modelo de clínica se caracteriza por um trabalho que prioriza o sujeito, a família e o contexto, e que tem por objetivo produzir saúde e aumentar a autonomia do sujeito, da família e da comunidade. Para isso, utiliza como meios de trabalho a integração da equipe multiprofissional, a adscrição de clientela e a construção de vínculo, a elaboração de projeto terapêutico conforme cada caso e a ampliação dos recursos de intervenção sobre o processo saúde-doença.

Nessa perspectiva, a terapêutica não se restringe somente a tratamentos farmacológicos ou cirurgia, mas leva em conta também o poder terapêutico da escuta e da palavra, o poder da educação em saúde e o apoio psicossocial ${ }^{7}$.

Contudo, na experiência da acadêmica, o tipo mais frequente de atendimento fornecido foi o clínico, ou seja, aquele realizado em consultório, quando comparado aos realizados em domicílio e/ou em conjunto com outros profissionais. Isto evidencia a falta de clareza dos objetivos do trabalho da Fonoaudiologia pautada no modelo de matriciamento, bem como uma demanda reduzida para atendimento em forma de atenção domiciliar. É válido referir que a carga horária de trabalho do profissional fonoaudiólogo (professor supervisor) e da estagiária, por vezes, não coincidia com os horários dos profissionais da equipe da ESF, prejudicando o trabalho e as discussões em equipe.

Outra questão referente aos muitos atendimentos clínicos e poucos de atenção domiciliar, discussões e elaboração de projetos terapêuticos pode estar relacionada com o tipo de formação acadêmica e a concepção de saúde e doença. Embora atualmente existam mudanças na formação, o modelo biologicista ainda é forte no meio acadêmico da área da saúde. E esse novo fazer clínico, esse pensar ampliado só será possível com mudanças no modelo tradicional, que tende a transformar o sujeito em um objeto inerte, que deve seguir sem restrições as prescrições e orientações da equipe de saúde à qual é submetido ${ }^{7}$.

O trabalho a ser realizado deveria estar pautado no conceito ampliado de saúde, que traz uma nova perspectiva de atuação profissional humanística, que tende a equilibrar a capacitação científica com os aspectos humanos do paciente e que, por sua vez, mexe com a cultura vigente e traz mudanças na forma de executar os serviços em saúde.

Entretanto, sabe-se que essas mudanças ocorrem segundo uma lógica organizacional, na qual é preciso também compreender que elas se darão, sobretudo, por mudanças de valores, de comportamento e pelo reconhecimento do outro como sujeito, por parte dos profissionais de saúde ${ }^{8}$. 
Durante o período de inserção da Fonoaudiologia no Nasf, também foram realizadas atividades de assessoria fonoaudiológica em dois Centros de Educação Infantil (CEI). Essas atividades incluíram orientação aos profissionais e aos pais dos alunos. Realizou-se ação conjunta com a Nutrição sobre orientação nutricional, oferta de alimento e hábitos orais. Os pais também eram orientados em uma roda de conversa sobre "família" e em horários de saída das crianças.

A educação em saúde é uma forma de atingir o cotidiano das pessoas por meio da disseminação do conhecimento científico produzido na área da saúde, transmitido por profissionais deste campo, o que possibilita a compreensão do processo saúde-doença, com o intuito de promover a adoção de novos hábitos e condutas de saúde 9 .

A relação estabelecida entre profissionais de saúde e de educação transpôs barreiras entre as duas grandes áreas. Isto permitiu mostrar a possibilidade de praticar a intersetorialidade em prol da promoção à saúde, tendo a integralidade como princípio norteador.

Este princípio implica uma visão ampliada do processo saúde-doença que afeta a individualidade e a coletividade, e pressupõe um conjunto de ações longitudinais, com foco na promoção, prevenção à saúde e reabilitação. Destaca-se que este princípio foi o orientador da ampliação e da qualificação das ações e serviços de saúde do SUS, com caráter intersetorial ${ }^{10}$.

$\mathrm{O}$ objetivo de prestar apoio matricial às três equipes de referência e, por consequência, realizar uma clínica ampliada não se pôde alcançar em sua plenitude. A estruturação da Fonoaudiologia na saúde coletiva, a clareza dos objetivos do Nasf, as poucas possibilidades de encontros entres os profissionais, a formação acadêmica e a concepção de saúde e doença foram fatores determinantes deste resultado. Entretanto, as observações, as vivências e as reflexões acerca desta atuação são fundamentais para a análise de práticas profissionais e o amadurecimento frente a propostas inovadoras como esta.

O Nasf é, sim, uma proposta inovadora e de grande potencial na saúde coletiva, porém apenas leituras dos documentos que o estabelecem não são suficientes para efetivá-lo. Portanto, pensar e repensar as práticas é imprescindível na busca pela integralidade.

\section{Visão pedagógica}

A lógica de atuação profissional predominante na área da saúde está pautada nos saberes e concepções da clínica médica tradicional, herança esta que considera o biológico e exclui o sujeito social.

Essa prática é justificada historicamente, pois a evolução do saber médico, bem como a construção da história da forma- ção médica convergiram para uma educação pautada na causa biológica da doença, sendo que este modelo de ensino é denominado flexneriano ${ }^{11}$

O modelo de Flexner é um conceito que vem sendo discutido após a elaboração de um relatório escrito por Abraham Flexner, que trouxe implicações para a medicina mundial, sendo considerado o maior responsável pela reforma da educação médica das escolas de Medicina do Canadá e Estados Unidos da América.

Nesse relatório, Flexner referiu que o estudo da Medicina deve ser centrado na doença de forma individual e concreta. Daí a razão de esse modelo de educação médica ser altamente biologicista.

Essa fragmentação do conhecimento nas diversas especializações ampliou e aprofundou o conhecimento, mas limitou a visão e se distanciou do ser humano como um todo em seu contexto $^{12}$

Porém, é importante levar em consideração o contexto em que esse modelo foi produzido, já que na época as escolas de Medicina vivenciavam um momento caótico e necessitavam de uma referência para organizar a formação dos profissionais da área médica.

No Brasil, esse modelo influenciou e continua influenciando a formação de profissionais da saúde. Tal fato é demonstrado por uma análise dos conteúdos programáticos das escolas médicas brasileiras, que revelaram uma hegemonia absoluta do entendimento do processo saúde-doença centrado em indivíduos biológicos ${ }^{13}$.

Pode-se dizer que esse modelo atualmente tem deixado a desejar em termos da integralidade do serviço para com o usuário, pois este último é prejudicado por não receber um atendimento que contemple suas reais necessidades. Este dado vai ao encontro do relato de que o modelo tecnicista-biologicista não tem dado conta de suprir as necessidades básicas da população ${ }^{11}$.

Atualmente, uma demanda crescente no contexto brasileiro é a humanização da assistência à saúde, que emerge de uma realidade em que os usuários dos serviços de saúde se queixam dos maus-tratos de que são vítimas. Do mesmo modo, a mídia denuncia aspectos negativos dos atendimentos prestados à população, e as publicações científicas comprovam a veracidade de muitos desses fatos ${ }^{14}$

A questão é que os serviços de saúde têm mostrado pouca capacidade de resolubilidade frente às necessidades de saúde dos indivíduos, sem criação de vínculos e responsabilizações, com dificuldades de acesso, numa prática marcada pela frieza e pouco participativa ${ }^{15}$

Por essas evidências, percebe-se que a Atenção Básica é um dos últimos lugares em que um acadêmico da área da saú- 
de pensa em atuar. Isto se deve ao fato de que, ainda fora da faculdade, cria-se uma concepção "errônea" da atuação profissional neste campo. Dessa forma, o aluno entra na faculdade com um preconceito estabelecido, e, à medida que vai tendo contato com as disciplinas que abordam tal assunto, o preconceito vai se confirmando, pois a prática e a realidade ficam muito distantes uma da outra.

Na verdade, esse cenário de prática foi desconhecido por muito tempo, e muitos o desvalorizam durante a formação acadêmica, inclusive no curso de Fonoaudiologia.

Pode-se exemplificar esse fato com a criação de uma Liga Acadêmica de Saúde Coletiva em 2008, com base na experiência vivenciada no projeto piloto no Nasf e na participação junto à oficina do Fnepas. Essa Liga reuniu alunos de vários períodos dos cursos de Fonoaudiologia, Medicina, Psicologia, Fisioterapia e Nutrição com o intuito de trabalhar com as concepções de integralidade, de forma a desenvolver um projeto de interdisciplinaridade agindo diretamente na formação acadêmica. Em poucos encontros, cerca de 60 alunos participavam e traziam consigo a vontade de fazer e ser a diferença na sua profissão.

Merece destaque a situação vivenciada durante a divulgação do trabalho da Liga e que foi motivo de questionamentos quanto à formação. Sempre que se falava da Liga para um grupo de alunos, alguns comentavam: "Ah, Liga de Saúde Coletiva? Tem a ver com saúde pública, né?" Chegava a ser um tanto engraçado, pois o desapontamento era visível no rosto dos acadêmicos. Tal situação mereceu uma reflexão a respeito de como o tema da saúde coletiva é apresentado aos alunos. A não diferenciação entre saúde pública e saúde coletiva era evidente entre os alunos dos diversos cursos da área da saúde que participavam da Liga. Saúde pública e saúde coletiva no grupo eram sinônimos.

O desgosto pela saúde pública/saúde coletiva e o preconceito em relação ao campo de atuação ganham fôlego com as formas de apresentação deste campo por meio das disciplinas estritamente teóricas e expositivas que enfatizam as NOBs, as leis e se esquecem do foco, o usuário.

A perspectiva tradicional do ensino na educação superior acaba por não operar com estratégias didático-pedagógicas, com modos de ensinar problematizadores, construtivistas ou com atuação ativa dos estudantes ${ }^{16}$, resultando neste nó crítico para a formação do profissional de saúde.

Particularmente nesta experiência, ressalta-se o potencial da prática para a teorização, uma vez que o começo do estágio se deu quando a acadêmica estava no terceiro período e não tinha a mínima ideia do que poderia fazer na Atenção Básica — apesar de já ter cursado algumas disciplinas em que o cur- rículo trazia como conteúdo a saúde coletiva. Na verdade, parece que, quando acadêmicos passam da teoria para a prática, o medo de errar faz pensar que tudo o que já se aprendeu não é suficiente para praticar a profissão plenamente.

Acredita-se que esse sentimento seja influenciado pela forma de ensino tradicional na qual os estudantes vêm sendo formados, descrita por Freire como pedagogia bancária. Nesta lógica, os conteúdos são "depositados" nos estudantes, que estudam por livros-textos ou anotações de aula, em detrimento do estímulo do desenvolvimento de habilidades de raciocínio e aplicabilidade de conhecimento. Parece existir uma regra positivista de que primeiro se precisa saber, para só depois poder fazer ${ }^{17}$.

Entretanto, com o tempo, esse sentimento muda e se transforma no que de fato é. Passa-se a entender que nunca se saberá tudo e que a prática nos levará a viver o que até então estava no papel, fazendo também com que o aluno queira buscar o reforço teórico e os fundamentos científicos para embasar essa prática.

As práticas germinam teorias, isto é, quando se age, é provável deparar-se com obstáculos ao movimento - do pensamento, da intervenção social, entre outros - e é necessário superá-los ou contorná-los para que a ação se desdobre e ganhe densidade ${ }^{18}$.

Neste sentido, trata-se de uma formação na qual a teorização se faz a partir do que reverbera nas práticas profissionais, o que exige articulação entre atores, saberes e práticas clínicas, uma vez que as questões de saúde dizem respeito aos acontecimentos sociais, as suas intricadas maquinações ${ }^{19}$.

O diferencial está na oportunidade de vivenciar logo no início o que a maioria só costuma experimentar no final da faculdade. É possível que durante a formação as concepções mudem, mas o tempo que poderia ser gasto vivenciando a prática e conhecendo uma realidade maior foi desperdiçado com inúmeras reclamações das disciplinas.

Nesse sentido, é importante reconhecer que, para formar profissionais com visão ampliada sobre o sistema de saúde, é necessário se apossar das iniciativas e programas governamentais direcionados para mudanças nas práticas de ensino. Além disso, enfatiza-se o fato de o perfil "generalista" ser o norteador na formação de tais propostas, uma vez que este tem sido o foco na busca por profissionais em todas as instâncias.

Assim, a estratégia para gerar mudanças de tais concepções é fazer com que os acadêmicos experimentem o que é atuar na Atenção Básica. Acredita-se que o contato deles com os pacientes, com outros profissionais e com as práticas exercidas por estes fará com que a realidade seja vivenciada junto com a teoria, o que também auxiliará a entender o funcionamento do Sistema Único de Saúde. 
É preciso começar a trabalhar na direção do envolvimento do fonoaudiólogo com a política de saúde para que não se incorra no erro de formar um profissional que queira atuar apenas em saúde pública sem preparo para isto. Tal afirmação pode e deve ser compreendida por todos os profissionais de saúde, a fim de atuarem de forma mais integral e humana.

\section{Visão pessoal}

Durante todo o ano de 2008, a vivência com o trabalho em grupo, o saber escutar e muitas vezes renunciar à própria verdade foram aprendizados essenciais. Acima de tudo, foi possível perceber que ser profissional da saúde não depende somente de saber fazer um bom diagnóstico ou ter uma boa técnica, mas depende principalmente do saber se relacionar. Parece até irônico, justamente para profissionais da comunicação, que isso pareça supérfluo ou pouco relevante. Não é necessário decorar toda a Portaria do Nasf para compreender que a integralidade (uma das suas propostas) depende em grande parte de relacionamentos ou, nas palavras de $\mathrm{Mehry}^{20}$, de tecnologias leves, aquelas relacionais no espaço intersubjetivo do profissional de saúde e do paciente.

É preciso conhecer a dinâmica de trabalho de uma Unidade Básica de Saúde, compreendendo o papel e a importância de cada profissional no trabalho da equipe. Para tanto, é fundamental entender a importância de trabalhar em grupo, de forma que todos partilhem do mesmo objetivo, no caso a atenção ao indivíduo e à comunidade ${ }^{21}$.

Nesse sentido, vale referir que a necessidade de trabalhar em equipe requer o entendimento do complexo processo saúde-doença.

Em todo o tempo de estágio, aprende-se demais com os profissionais de outras áreas e com os próprios pacientes. $\mathrm{Na}$ visão da acadêmica, não se passou um dia sequer sem que algo novo fosse experimentado, isto é, em todos os estudos de casos, reuniões, atenção domiciliar, atendimentos em grupo, oficinas de educação em saúde, sempre houve algo a aprender. Tais aspectos funcionaram como instrumento de renovação e motivação para o aprendizado.

\section{CONSIDERAÇÕES FINAIS}

A inserção da Fonoaudiologia no Nasf no período de 2008 possibilitou a vivência da realização do fazer fonoaudiológico na Atenção Básica. Vale destacar que este projeto de extensão ocorreu por apenas um ano, pelos seguintes motivos: o projeto não tinha sustentabilidade e estava sujeito à transitoriedade como extensão, ao invés de se concretizar como uma prática curricular de ensino; havia vários entendimentos a respeito do projeto, possibilitando práticas distintas e desconexas com a proposta da Portaria; o projeto não se efetivou como uma vi- vência interdisciplinar integral devido a problemas ligados à carga horária dos profissionais tutores, com poucas possibilidades de encontros entre a própria equipe tutorial e com profissionais da Equipe de Estratégia de Saúde da Família, bem como de seus respectivos estagiários.

Entretanto, durante esse período, dentro do possível, pôde-se atuar de forma interdisciplinar, já que se estabeleceu uma relação entre os vários profissionais de saúde e as três equipes de saúde da família, integrantes do DDA. O agir interdisciplinar evidenciou algumas dificuldades, mas é importante enfatizar que a implantação dessa forma de atuação está em processo.

Teve-se, ainda, a experiência da intersetorialidade, quando se interligou saúde e educação — uma forma de consolidar a prática da integralidade.

Por toda essa vivência, é possível dizer que, para poder realizar um bom trabalho na Atenção Básica, em primeiro lugar é fundamental ter claro que o tipo de serviço a ser desenvolvido não deve ser clínico, aquele tradicional, o serviço da especialidade. É preciso pensar e agir em favor de uma concepção de clínica ampliada. Além disso, é necessário se apropriar de um lugar na equipe, pois o Nasf prevê que o fonoaudiólogo realize projetos, construindo uma prática específica e ao mesmo tempo plural, em benefício das comunidades.

Saber agir de forma interdisciplinar, conhecer profundamente o trabalho que está sendo realizado, repensar e refletir sobre nossas concepções e práticas, bem como saber se relacionar proporcionará a garantia desse lugar e o surgimento de novas oportunidades de atuação.

Desta forma, acredita-se que este artigo propicie uma reflexão quanto à necessidade de discutir mais sobre as práticas de saúde coletiva dentro da própria equipe de saúde, na tentativa de materializar o SUS e efetivar a tão sonhada proposta de apoio matricial.

Além disso, a análise das experiências de atuação da Fonoaudiologia e demais profissões junto à Saúde da Família merece ser acompanhada e avaliada de perto, por ser uma promissora proposta de ampliação do acesso da população à Atenção Integral à Saúde.

É inegável que a Fonoaudiologia e o fonoaudiólogo têm muito a fazer pela saúde das pessoas e este deve se preparar para o trabalho em equipe na Atenção Básica.

\section{REFERÊNCIAS}

1. Mendes VL. Editorial. Rev soc bras fonoaudiol. 2009; 14(1):129-35.

2. Penteado RZ, Servilha EAM. Fonoaudiologia em saúde publica / coletiva: compreendendo prevenção e o paradig- 
ma da promoção da saúde. Distúrbios da comunicação. 2004; (1):107-116.

3. Wertzner HF. Ambulatorios de fonoaudiologia em unidades básicas de saúde. In: Befi D, org. Fonoaudiologia na atenção primária à saúde. São Paulo: Lovise; 1997. p.161176.

4. Silva JR AG, Merhy EE, Carvalho LC. Construção da integralidade: cotidiano, saberes e práticas em saúde. In: Pinheiro R, Mattos RA. Os sentidos da integralidade: na atenção e no cuidado à saúde. Rio de Janeiro: UERJ, IMS: ABRASCO; 2003. p.113-29.

5. Organização Mundial de Saúde. Carta de Ottawa para a Promoção da Saúde: $1^{a}$ Conferência Internacional sobre Promoção da Saúde. [capturado 05 out. 2010]. Otawa (Canadá): OMS; 1986. p. 38-43. Disponível em: <http:/ / www. who.int/hpr/backgroundhp/ottawacharter.htm>

6. Brasil. Secretaria de Gestão do Trabalho e da Educação na Saúde. Seleção para o Programa de Educação pelo Trabalho para a saúde (PET-SAÚDE). Edital no 12. Brasília, set.2008. p.81-82.

7. Campos GWS, Amaral MA. A clínica ampliada e compartilhada, a gestão democrática e redes de atenção como referenciais teórico-operacionais para a reforma do hospital. Ciênc. saúde coletiva [online]. 2007; 12(4) [capturado 10 out.2012]; 849-859. Disponível: < http://www.scielo.br/ s cie lo.p h p ? s c ri p t = s ci_ar t t ext \& pid $=$ S1413-81232007000400007>

8. Panizzi M, Franco TB. A implantação do Acolher Chapecó. Reorganizando o processo de trabalho. [capturado 09 out.2010]. São Paulo; [200-?]. Disponível em: <http://pt. scribd.com/doc/48743570/ACOLHER-CHAPECO-Tulio-Franco >

9. Alves VS. Um modelo de educação em saúde para o Programa Saúde da Família: pela integralidade da atenção e reorientação do modelo assistencial. Interface [on line]. 2005; 9(6) [capturado 07 abr. 2009]; 39-52. Disponível em: < http: / / www.scielo.br/scielo.php?pid=S1414$-32832005000100004 \&$ script $=$ sci_arttext\&tlng $=$ pt $>$.

10. Vasconcelos CM, Pasche DF. O sistema único de saúde. In: Campos GWS. Tratado de saúde coletiva. 2.ed. São Paulo: Hucitec; Rio de Janeiro: FIOCRUZ; 2008. p.531-545.

11. Arcoverde TL. (Des)construção do sentido da profissão: a trajetória da representação social. Blumenau; 2004. Mestrado [Dissertação] — Fundação Universidade Regional de Blumenau.
12. Lampert JB. Na transição paradigmática da educação médica: o que o paradigma da integralidade atende que o paradigma flexneriano deixou de lado. Boletim da ABEM. 2003;31(4/5).

13. Comissão Interinstitucional Nacional de Avaliação das Escolas Médicas. Relatório final da II fase do projeto de avaliação da educação médica no Brasil. Rio de Janeiro: Cinaem; 1997. (Relatório)

14. Hoga LAK. A dimensão subjetiva do profissional na humanização da assistência à saúde: uma reflexão. Rev. esc. enferm. 2004; 38(1):13-20.

15. Maeyama MA, org. A construção do acolhimento: a proposta de mudança do processo de trabalho em saúde do município de Bombinhas. Bombinhas, SC: Secretaria Municipal de Saúde de Bombinhas; 2007.

16. Feuerwerker LCM. Além do discurso da mudança na educação médica: processos e resultados. São Paulo: Hucitec; Londrina: Rede Unida; Rio de Janeiro: Associação Brasileira de Educação Médica; 2002.

17. Maia JA. Currículo no ensino superior em saúde. In: Batista NA, Batista SH. Docência em saúde: temas e experiências. São Paulo: SENAC; 2004. p.101-34.

18. Deleuze G, Guattari F. O que é filosofia? In: Mendes VLF. Uma clínica no coletivo: Experimentações no Programa de Saúde da Família. São Paulo: Hucitec; 2007.

19. Mendes VLF. Uma clínica no coletivo: Experimentações no Programa de Saúde da Família. São Paulo: Hucitec; 2007.

20. Merhy EE. Saúde: a cartografia do trabalho vivo. São Paulo: Hucitec; 2002. 189 p.

21. Vasconcelos EM. A priorização da família nas políticas de saúde. Saúde em Debate. 1999; 23(53): 6-19.

\section{CONTRIBUIÇÃO DOS AUTORES}

Os autores participaram da concepção, análise de resultados e contribuíram efetivamente na realização do artigo.

\section{CONFLITO DE INTERESSES}

Declarou não haver.

\section{ENDEREÇO PARA CORRESPONDÊNCIA}

Inajara Carla Oliveira

Rua Concórdia, nº 561

São Vicente - Itajaí - SC

CEP: 88309-645

E-mail: ina_carla@hotmail.com 